\title{
PROJECT PORTFOLIO SELECTION THROUGH DECISION SUPPORT
}

\author{
by \\ F. Ghasemzadeh and \\ N. P. Archer \\ Management of Innovation and New Technology - \\ Research Centre \\ WORKING PAPER NO. 76
}

1998

Innis The Working Paper series is intended as a means whereby a researcher may communicate his or her

HD thoughts and findings to interested readers for their comments. The paper should be considered preliminary in nature and may require substantial revision. Accordingly, this Working Paper should not be quoted nor the data referred to without the written consent of the author. Your comments and suggestions are welcome and should be directed to the author.

no. 76 


\title{
Project Portfolio Selection Through Decision Support
}

\author{
by \\ F. Ghasemzadeh and N.P Archer \\ Michael G. DeGroote School of Business \\ McMaster University \\ Hamilton, Ontario, Canada, L8S 4M4
}

\section{ABSTRACT}

Project portfolio selection is a crucial decision in many organizations which must choose, from a variety of possible investments of available resources, those which can best meet organizational objectives. For example, firms involved in engineering, construction, or new product development, and many firms investing in information technology projects, often have more proposed projects than resources to support them. They must make informed decisions where the appropriate distribution of investment is complex, due to varying levels of risk, resource requirements, and interaction among the proposed projects. In previous work we have suggested a framework that builds on the strengths of existing project selection methods to help overcome the complexity of project portfolio selection, by simplifying the process through a logical series of steps. This process can be adapted to use those techniques preferred by the organization, and it lends itself to computer decision support. In this paper we discuss the implementation of the on-line portion of our framework in the form of a decision support system (DSS) which we call PASS (Project Analysis and Selection System). We describe the results of laboratory tests undertaken to measure its usability and the quality of its results, compared to manual selection processes, in typical portfolio selection problems. We also discuss the potential of PASS in supporting corporate decision making, through exposure this system has received at several interested companies.

Key Words: Decision Support Systems, Portfolio, Project Management, Integer/Binary Program, Human-Computer Interaction 


\section{INTRODUCTION}

Project portfolio selection is the periodic activity involved in selecting a portfolio of projects, that meets an organization's stated objectives without exceeding available resources or violating other constraints. Some of the issues that have to be addressed in this process are the organization's objectives and priorities, financial benefits, intangible benefits, availability of resources, and risk level of the project portfolio (Schniederjans and Santhanam, 1993).

Difficulties associated with project portfolio selection result from several factors: 1) there are multiple and often-conflicting objectives, 2) some of the objectives maybe qualitative, 3) there is a large amount of uncertainty and risk that should be addressed, 4) the selected portfolio may need to be balanced in terms of important factors, such as risk and time to completion, 5) some projects may be interdependent, and 6) the number of feasible portfolios is often enormous.

In addition to these difficulties, due to resource limitations there are usually constraints such as finance, work force, and facilities or equipment, to be considered. As some researchers have noted (Lucas, 1973), the major reason why some projects are selected but not completed is that resource limitations are not always formally included in the project selection process. In cases where resource limitations are at fault for a failed project, a selection model that incorporated resource limitations could have aided the decision maker in avoiding such mistakes (Schniederjans and Santhanam, 1993). Portfolio selection becomes more complex when resource availability and consumption are not uniform over time.

There are more than one hundred divergent techniques that can be used to estimate, evaluate, and choose project portfolios (Cooper, 1993; Dos Santos, 1989). Many of these techniques are not widely used because they address only some of the above issues, they are too complex and require too much input data, they may be too difficult for decision makers to 
understand and use, or they may not be used in the form of an organized process (Cooper 1993). Among all of the techniques that are available, optimization techniques are the most fundamental quantitative tool for project portfolio selection (Jackson, 1983) that address most of the important issues. However, they have largely failed to gain user acceptance (Mathieu and Gibson, 1993), and few modeling approaches, from a variety of optimization approaches that have been developed, are being utilized as aids to decision making in this area (Liberatore and Titus, 1983). According to Hess (1993) "management science has failed altogether to implement project selection models; we have proposed more and more sophistication with less and less practical impact". One of the major reasons for the failure of traditional optimization techniques is that they prescribe solutions to portfolio selection problems without allowing for the judgment, experience and insight of the decision maker (Mathieu and Gibson, 1993).

A literature review that we conducted in this field (Archer and Ghasemzadeh (a), 1996) clearly showed that, although there are many different methods for project evaluation and portfolio selection that have their own advantages, no single technique addresses all of the issues that should be considered in project portfolio selection. Among published methodologies for project portfolio selection, there has been little progress towards achieving an integrated framework that: a) simultaneously considers all the different criteria in determining the most suitable project portfolio, b) takes advantage of the best characteristics of existing methods by decomposing the process into a flexible and logical series of activities and applying the most appropriate technique(s) at each stage, and c) involves full participation by decision makers. This is partly because of the complexities involved in project portfolio selection, as explained before. A few attempts to build integrated support for portfolio selection have been reported (Hall and Nauda, 1990; De Maio et al, 1994; Kira et al., 1990). However, these have been limited and 
specific to the methods used, rather than providing flexible choices of techniques and interactive system support for users.

In an attempt to overcome these difficulties, we have developed an integrated framework for project portfolio selection, which takes advantage of the best characteristics of some of the existing methods (Archer and Ghasemzadeh (b), forthcoming). The proposed framework combines methods which have a good theoretical base with other methods that may not be strong theoretically, but which are commonly used because of their desirable decision support characteristics. The framework includes a staged approach, where the most relevant and appropriate methods can be selected by the organization and used at each stage.

In order to increase the likelihood of user acceptability, we use a decision support approach to project portfolio selection (Bard et al., 1988; Liberatore and Titus, 1983). This approach is consistent with the recent shift of researcher interest from solving well-structured problems under often unrealistic assumptions, to developing decision support systems that support decision makers in capturing and making explicit their own actual preferences, interacting with them in several steps of decision making (Dyer et al., 1992).

In the following, first we describe the proposed framework briefly. The model which manages optimization and interaction, among the projects available for the portfolio during online decision making, is outlined. Then, in order to demonstrate the potential of the framework, we describe a prototype decision support system, called PASS (Project Analysis and Selection System), that we developed for this purpose. A set of hypotheses are developed to test PASS usefulness, perceived usefulness and perceived ease of use. The experimental design and results of lab experiments are discussed. Finally, we outline some of the additional work needed to address some related and unsolved issues in project portfolio selection. 


\section{A FRAMEWORK FOR PROJECT PORTFOLIO SELECTION}

In this section we briefly describe an integrated framework for project portfolio selection that takes advantage of the best characteristics of existing methods. The proposed framework combines the methods that are well grounded in theory and those that are easy to understand, and applies them in a logical order (for details see Archer and Ghasemzadeh (b), forthcoming).

Project portfolio selection should be considered as a process that includes several related steps, rather than just evaluating or scoring projects, or solving an optimization problem. The proposed framework consists of discrete stages. A pre-process stage provides high level guidance to the portfolio selection process. These include Strategy Development (determination of strategic focus and setting resource constraints), and Methodology Selection (choosing the techniques to use for portfolio selection). Strategy development may be carried out at higher managerial levels than the portfolio selection committee, since it involves the firm's strategic direction. Selecting methodologies that suit the project class at hand, the organization's culture, problem-solving style, and project environment, must also be done in advance.

The five major stages of the proposed framework can be divided into off-line and on-line activities. The first three stages (pre-screening, individual project analysis, and screening) are off-line activities that can be performed by decision analysts. Pre-screening applies guidelines developed in the strategy development stage to ensure that any project being considered fits the strategic focus of the portfolio, has undergone a preliminary analysis, and has a champion to ensure its implementation if chosen. At the Individual Project Analysis stage a common set of parameters, such as net present value and rate of return, is calculated for each project. And finally during the Screening stage, project attributes from the previous stage are examined to eliminate any projects which do not meet pre-set criteria such as estimated rate of return. The 
intent of pre-screening and screening stages is to eliminate any non-starters and reduce the number of projects to be considered.

The last two stages (optimal portfolio selection and portfolio adjustment), the major focus of this paper, can be performed in an on-line session directly by decision makers through an appropriate decision support system. At the Optimal Portfolio Selection stage, when there is more than one objective involved in decision making, first the quantitative and qualitative objectives are integrated by means of a weighted value function, and reduced to one objective. Then an optimization model is applied that considers resource limitations, timing, project interdependences, balancing criteria, and other constraints, and maximizes total portfolio benefit. Portfolio Adjustment is the final stage of the process, which enables decision makers to apply their knowledge and experience and make adjustments to the portfolio by adding or deleting projects. Once the user makes such changes to the portfolio to make it more acceptable, it is necessary to re-cycle back to re-calculate portfolio parameters such as project schedules and time-dependent resource requirements.

\section{OPTIMAL PORTFOLIO SELECTION}

Optimal portfolio selection is a major stage in the framework. It consists of two phases. The first phase applies only when projects are characterized by multiple objective functions. It is used to integrate the multiple objectives into a single objective function which is the relative value of each project, and is input to the second phase. If projects have a single objective, such as net present value or expected net present value, this can be input directly into the second phase. When there are multiple objectives we suggest that the objectives be approximated as additive value functions, using expected values as certainty replacements where necessary for stochastic elements. The decomposition form of such objectives requires the assumption of 
mutual preference independence. Any related risk characteristics are not discarded, but are carried forward as attributes to be used in balancing portfolio risk in the final adjustment stage.

There are a number of techniques that can be used for multiple objective problems in the first phase of optimal portfolio selection. We will mention a few, including linear goal programming. However, most projects are characterized by both objective and judgmental criteria, and goal programming is best suited to situations involving objective criteria. Arguably the most widely used technique for value determination, where there are multiple criteria of both types, is weighted scoring. Here, each criteria is weighted according to its importance, and each candidate project is then scored on each criteria by the decision maker(s). The sum of the weighted scores for each project is then the relative value of the project. The aspect of this technique which gives the greatest difficulty is weight determination. Another technique which is better at handling the weight determination problem is the analytical hierarchy process (AHP). In AHP (Saaty et al 1980) the criteria are decomposed into a hierarchy and the relative priority or importance of the elements at the bottom level are determined through pair-wise comparison by the decision maker(s). These are combined at the next higher level into relative priorities at that level, until the highest level is reached. A linear model is then derived, and used for weighting the criteria. If there are only a few projects, a pairwise comparison of alternative projects by criteria can be used at this point. However, many portfolio projects involve tens of projects, and the number of pairwise comparisons necessary would rule this out. Instead, the relative value of each project can be determined by using the weights already determined, after scores are supplied for the project on each criteria by the decision maker(s). AHP has been implemented in the form of a commercial software package called Expert Choice. 
The second phase of the optimization process is the application of an optimization model, using the single objective function values derived in phase one. We have chosen a zero-one integer linear programming (0-1ILP) model that maximizes the overall objective of the portfolio, while satisfying existing constraints. Together with the phase one process, this approach handles a) multiple, conflicting goals, b) qualitative or judgmental as well as objective criteria, and c) explicit constraints such as resource limitations and project interdependencies. We have also included the facility to perform portfolio balancing in an interactive manner, to handle nonuniform resource consumption over time, and to select and schedule the optimal set of projects that will maximize overall benefit, based on the relative value of the projects being considered.

The decision variables, objective function, and constraints of the 0-1 ILP model are as follows:

Decision Variables- The decision variables of the model are defined by:

$X_{i j}= \begin{cases}1 & \text { if project } \mathrm{i} \text { is included in the portfolio and starts in period } \mathrm{j} \\ 0 & \text { otherwise }\end{cases}$

for $\mathrm{i}=1, \ldots, \mathrm{N}$, where $\mathrm{N}$ is the total number of projects being considered, and $\mathrm{j}=1, \ldots, \mathrm{T}$, when the planning horizon is divided into $\mathrm{T}$ periods.

Objective Function- The objective function is given by

Maximize $Z=\sum_{i=1}^{\mathrm{N}} \sum_{j=1}^{T} a_{i} X_{i j}$

where $\mathrm{Z}$ is the value function to be maximized, and $a_{i}$ is the potential benefit from project $\mathrm{i}$.

Constraints- The following set of constraints will guarantee that each project, if selected, will not start twice during the planning horizon.

$$
\sum_{j=1}^{T} X_{i j} \leq 1 \quad \text { for } \mathrm{i}=1, \ldots, \mathrm{N}
$$


Appropriate sets of constraints can be established for each limited resource such as finance, work force and machine time. The amount of resource available to carry out a set of projects may vary over time. For example, if the planning horizon is divided into $\mathrm{T}$ planning periods, and the maximum allowed cost for all projects during period $\mathrm{k}$ should not exceed a certain amount $\left(\mathrm{AF}_{\mathrm{k}}\right)$, then the set of constraints would be

$$
\sum_{i=1}^{N} \sum_{j=1}^{k} C_{i, k+1-j} X_{i j} \leq A F_{k} \quad \text { for } \mathrm{k}=1, \ldots, \mathrm{T}
$$

where $\mathrm{AF}_{\mathrm{k}}$ is the total financing available in period $\mathrm{k}$ and $C_{i, k+1-j}$ is the financing required by project $\mathrm{i}$ in period $\mathrm{k}$. Note that if project $\mathrm{i}$ starts in period $\mathrm{j}$, it is in its $(\mathrm{k}-\mathrm{j}+1)_{\mathrm{th}}$ period in period $\mathrm{k}$, and so will need $C_{i, k+1-j}$ units of financing. This constraint also guarantees that each project, if started, should continue to completion within the planning horizon.

All of the selected projects should finish within the planning horizon. The following set onstraints addresses this issue.

$$
\sum_{j=1} j X_{i j}+D_{i} \leq T+1 \quad \text { for } \mathrm{i}=1, \ldots, \mathrm{N}
$$

where $D_{i}$ is the duration of project $i$ (the number of periods it takes to complete project $i$ ).

Selection dependency and time dependency among projects can be considered in the model by the following sets of constraints. Constraint 5 guarantees the selection of its precursor projects, once a project is selected, and constraint 6 guarantees that all of the precursor projects will be finished before the successor project starts.

$$
\begin{aligned}
& \sum_{j=1}^{T} X_{i j} \geq \sum_{j=1}^{T} X_{l j} \\
& \sum_{j=1}^{T} j X_{l j}+(T+1) *\left(1-\sum_{j=1}^{T} X_{l j}\right)-\sum_{j=1}^{T} j X_{i j} \geq D_{i} \sum_{j=1}^{T} X_{i j}
\end{aligned}
$$


for $i \in P_{l}$, where $P_{l}$ is the set of precursor projects for a particular project $l, l=1, \ldots, \mathrm{L}$. If there are $\mathrm{P}$ sets of mutually exclusive projects (a set of projects from which only one can be included in the portfolio), and $S_{p}$ is the $p$ th set of such projects, then the set of constraints is:

$$
\sum_{i \in S_{p}} \sum_{j=1}^{T} X_{i j} \leq 1 \quad \text { for } p=1, \ldots, \mathrm{P}
$$

Many other types of constraints can be added to this model, depending on the situation at hand (Ghasemzadeh et al., 1996). Solving the model will select and schedule a portfolio of projects that maximizes the total benefit of the portfolio and satisfies all the constraints. Shadow prices are not applicable in 0-1 ILP models. As an alternative, because of the extreme sensitivity of the optimal solution to the constraint coefficients in integer programming models, the model should be re-solved several times with slight variations in the coefficients each time before attempting to choose an optimal solution for implementation (Anderson et al., 1994). We will discuss such a DSS in the following which implements the optimization and portfolio adjustment stages.

\section{PROJECT PORTFOLIO SELECTION THROUGH DSS SUPPORT}

As we can see from the foregoing sections, in all stages of the portfolio selection process, decision makers and analysts should be able to interact with the system, which provides models and data to support the decision process. Provision for continuous interaction between system and decision makers is important because: a) it is extremely difficult to formulate explicitly in advance all of the preferences of the decision makers, b) involvement of decision makers in the solution process indirectly motivates successful implementation of the selected projects, and c) interactive decision making has been accepted as the most appropriate way to obtain the correct preferences of decision makers (Mukherjee, 1994). 
If this interaction is to be supported by a computer-based system, then there is a need for a sub-system to manage the related techniques/models, another sub-system to support the data needs of the process, and finally a sub-system that acts as an interface between the decision maker and the system. This is a system which is equivalent conceptually to a DSS, or Decision Support System (Turban 1995). According to Turban "A Decision Support System (DSS) is an interactive, flexible, and adaptable computer-based information system, specially developed for supporting the solution of a non-structured management problem for improved decision making. It utilizes data, provides an easy-to-use interface, and allows for the decision maker's own insights".

A DSS to support the main stages in the framework requires a carefully designed model management module to handle models of the many different types which may be chosen. Its implementation requires considerations of model representation and integration. Integrated DSS modeling approaches include process integration (Dolk \& Kotteman 1993) where heterogeneous models (models from different paradigms) are to be integrated. The major issues that arise during process integration are synchronization and variable correspondence integration (Kotteman \& Dolk 1992). Synchronization deals with the order in which models must be executed, and timing of dynamic interactions among the models. Variable correspondence deals with input/output relationships among the component variables in the various models being used, and assuring dimensional consistency among these variables. In our DSS, models are not executed in parallel. They terminate after transferring their outputs for use by subsequent models, so synchronization is not a critical issue.

To handle variable correspondence, a central database is used. This acts as a data repository which is open to inspection by users during the portfolio selection process, and as a 
transfer site to provide matched data for the input and output variables of the various models being used. The database can be updated during the portfolio selection process through direct user input, interactions with associated project databases, and from the outputs of models and their components. Portfolio database updates also include relevant data extracted from other databases that relate to ongoing management of existing projects.

The DSS must also have a user-friendly interface, which hides the complexities of the system and its models from decision makers, and provides a bridge between users and other components of the DSS. It is used by decision makers to input data and decisions, to retrieve data from related databases, and to provide direction and control of the system. It also presents the results of computations to users and allows them to interact with the system to arrive at satisfactory solutions. User-friendliness is of critical importance because ease of use and user acceptance are significant determinants of intention to use a computer technology (Davis et al., 1989; Moore and Benbasat, 1991).

\section{DESIGN AND IMPLEMENTATION OF PASS}

We developed a prototype DSS called PASS (Project Analysis and Selection System) to support decision makers in project portfolio selection. The conceptual design of this system has been discussed elsewhere (Archer and Ghasemzadeh (c)). DSS support of project portfolio selection can be divided into off-line and on-line sessions. Decision analysts are the major players in the off-line sessions. Tasks such as data entry, pre-screening, individual project evaluation and scoring, screening, and optimization model definition can be performed in offline sessions with or without the direct involvement of decision makers. Commercially available software packages such as spreadsheets can be used for these purposes. In the on-line sessions, the most important stages of the framework (optimal portfolio selection, and portfolio 
adjustment) are performed directly by decision makers. The current version of PASS supports decision makers in the on-line session.

PASS initially applies an optimization model to find an optimal solution, which maximizes the benefit(s) of interest. At the present time net present value (NPV) and Expected NPV (ENPV) are available, but this can be expanded to a variety of benefit measures. Solutions are presented to decision makers on a portfolio matrix display (Figure 1) and used as starting points for decision makers to reach satisfactory portfolios through interactions with PASS. A portfolio matrix display style is used since it displays the end product of the selection process, and is more understandable by users. Cooper et al. (1997) present different types of portfolio matrices that can be used at this stage. PASS also provides decision makers with a Gantt chart that shows a project implementation schedule based on the output of the optimization model.

*** Insert Figure 1 about here***

PASS not only supports the intuition of the decision makers in the process, but it also eliminates the development of, and direct interaction with, complex models, which are typically developed by decision analysts in advance during off-line sessions. This eliminates a major obstacle that often inhibits managers from using more sophisticated models at the strategic level, and enhances the possibility of system use by higher level managers.

Decision makers, who are active elements in the decision making process, can also use PASS to perform sensitivity analysis in order to examine the robustness of the solution to changes in different variables and parameters. In addition, optimal solutions that are proposed by the system can be modified by adding or dropping different projects to find a more balanced and intuitively satisfactory portfolio. Moreover, PASS allows decision makers to observe the 
resulting impact of any proposed changes on the optimality of the solution and on the availability of required resources.

During the adjustment stage, PASS prevents decision makers from selecting or deselecting a project when certain constraints, such as resource limitations or interdependence among projects, are binding the decision maker; the system also provides the user with the necessary feedback in such situations. The final portfolio that decision makers choose might not be optimal. However, this should not be a critical issue as long as the decision makers know how far the selected portfolio is from the optimal portfolio initially recommended by the system, and how much of each resource is actually required.

\section{HYPOTHESES AND EXPERIMENTAL DESIGN}

When PASS was developed, an important issue was to determine whether the system would be useful, and to investigate user perceptions of its usefulness and ease of use. A positive perception about usefulness of the system does not necessarily mean that the system helps decision makers to make better decisions. However, if test results show that users do not perceive PASS as a useful tool, even if it really offers better solutions, its perceived usefulness needs to be improved. Users are not likely to use a system unless they perceive it as a useful and easy to use tool (Davis et al., 1989; Davis, 1989; Moore and Benbasat, 1991).

\subsection{Hypotheses}

The following three hypotheses were developed to test the usefulness of PASS, as well as user perceptions of its usefulness and ease of use. The first hypothesis concerns the improvement of project portfolio decisions when using PASS versus normal Manual Methods (MM). The second and third hypotheses examine the perceived usefulness and perceived ease of use of PASS. In optional use situations, which are typical for systems such as PASS, users may avoid 
using the system if they do not perceive it to be useful and easy to use. Even in mandatory use situations or when there is no other alternative but to use PASS (captive situation), perceived usefulness and perceived ease of use can enhance user satisfaction (Adams et al., 1992).

Hypothesis 1: The use of PASS improves the quality of project portfolio selection decisions.

$\mathrm{H}_{0}: \mathrm{PFB} \leq 0.5$

$\mathrm{H}_{1}: \mathrm{PFB}>0.5$

where PFB is the probability of finding a portfolio with PASS which is better than the portfolio found by the manual method (MM). We define a higher quality decision as selection of a portfolio that: 1) provides more benefits overall, 2) is better balanced, 3) considers interdependencies among projects, and 4) satisfies resource constraints.

Hypothesis 2: Users perceive PASS as a useful tool for project portfolio selection.

This hypothesis deals with the perceived usefulness of PASS and was tested by the following sub-hypotheses, using responses to questions 1 to 4 in a questionnaire (Appendix).

$\mathrm{H}_{2.1}$ : PASS helps to accomplish project portfolio selection more quickly than MM. $\mathrm{H}_{2.2}$ : PASS improves project portfolio selection decisions. $\mathrm{H}_{2.3}$ : PASS makes it easier to do project portfolio selection. $\mathrm{H}_{2.4}$ : Overall, $P A S S$ is a useful tool for project portfolio selection

The null and alternative hypotheses are stated below. A seven point Likert scale was used for measurement in the questionnaire. A score of 4, which has been used in the following, indicates the middle (neutral) point on each scale, and $\mathrm{M}_{\mathrm{i}}$ is the estimated median of responses to question i $(1 \leq \mathrm{i} \leq 4)$.

$\mathrm{H}_{0}: \mathrm{M}_{\mathrm{i}} \leq 4$

$\mathrm{H}_{1}: \mathrm{M}_{\mathrm{i}}>4$

Hypothesis 3: Users perceive PASS as an easy-to-use tool. 
- This hypothesis deals with the perceived ease of use of PASS and was tested by the

following six sub-hypotheses using responses to questions 5 to 10 in the questionnaire.

$\mathrm{H}_{3.1}$ : It was easy to learn PASS.

$\mathrm{H}_{3.2}$ : It was easy to get PASS to do what I wanted to do.

$\mathrm{H}_{3.3}$ : PASS was clear and understandable.

$\mathrm{H}_{3.4}$ : PASS was flexible to interact with.

$\mathrm{H}_{3.5}$ : It would be easy to become skillful at using PASS.

$\mathrm{H}_{3.6}$ : Overall, PASS is easy to use.

The null and alternative hypotheses are stated below. A score of 4 indicates the middle point on the scale, and $M_{i}$ is the estimated median of responses to question $i(5 \leq i \leq 10)$.

$\mathrm{H}_{0}: \mathrm{M}_{\mathrm{i}} \leq 4$

$\mathrm{H}_{1}: \mathrm{M}_{\mathrm{i}}>4$

We applied tests of these hypotheses to both small and larger problems. We define small problems as problems with five candidate projects (or less) to be selected over a time horizon of ten periods (or less) and larger problems as problems with more than five projects to be selected and scheduled over at least ten periods.

\subsection{Experimental Design}

Two project portfolio cases were developed. The first test case (Acme) represents a small problem in which subjects were asked to select a portfolio from a list of 4 candidate projects and schedule them within a 10 period time horizon. The second case (Merritt) represents a larger problem in which subjects were asked to select a portfolio from a list of 12 candidate projects and schedule them within a 10 period time horizon. Since the solution space for project portfolio selection problems is usually huge, finding the optimal solution manually can be difficult. For example, since in the Merritt Case the number of projects and periods is 12 and 10 successively, and since each project can be selected or not selected in each period, the number of possible combinations is $2^{120}$. It should be noted that, due to real world considerations, the number of 
alternative solutions is usually much less, but a large solution space still must be searched in order to find the global optimal solution. For example, if we impose a constraint related to project length, where projects must be completed during the planning horizon, the number of feasible solutions reduces to $\prod_{i=1}^{N}\left(T-D_{i}+2\right)$ where $\mathrm{N}$ and $\mathrm{T}$ are the total number of projects and periods respectively, and $D_{i}$ is the duration of project $i$.

Due to the size of the solution space in project portfolio selection problems, although PASS can easily solve larger and more complex problems, in this experiment we simplified the cases to reduce frustration of subjects when solving the problem. For example, in the larger problem (Merritt) a company wants to select a portfolio of projects from a list of 12 candidate projects and schedule them within a ten period time horizon to maximize the total benefits. Some of the major issues that the company should address include: 1) total and periodic budget limitations, 2) balancing the portfolio in terms of risk and time to complete (the company does not want too much investment in high risk or long term projects), 3) some projects are interdependent, 4) projects selected must be able to be completed by the end of the ten period plan, and 5) projects, once started, cannot be interrupted. Many other types of issues might exist in a real case that can be addressed by adding appropriate sets of constraints to the optimization model.

The objective of developing these cases was to have one relatively straightforward portfolio problem (Acme) and one more complex one (Merritt), to compare the quality of manual versus PASS solutions for two quite different problems. In all cases subjects solved the case manually first, and then solved it with the help of PASS, to avoid biasing the results obtained in the manual part of the test towards the optimal PASS solutions. The subjects who received the Acme case were expected to solve it in about 20 minutes and those who received the Merritt 
case, in about 40 minutes. These timings were not rigidly enforced and participants could keep working on their case as long as they felt comfortable in continuing. After using PASS to obtain the optimal solution, the subjects performed a sensitivity analysis with PASS by increasing financial resources by $10 \%$. They also changed the balancing criteria and observed the impact of such changes on the optimal solution.

To reduce learning effects, and also to prepare the subjects for the test, we developed a simple case $(\mathrm{ABC})$ which consisted of three candidate projects that could be selected and scheduled within a 10 period time horizon, with few constraints. Solving this case with both the manual method and PASS helped the subjects to learn both methods before undertaking their assigned tasks.

Some participants, due to past experience, might have been more familiar with project selection and scheduling problems and the heuristics that could be applied for these kinds of problems than others. To decrease the impact of this potential difference among participants, a sheet was given to each subject which contained some heuristics for manually solving the case. The use of these heuristics was not mandatory and subjects could use any manual method they found to be useful.

In order to collect data on the variables of interest during the test, a test data sheet and a questionnaire (see Appendix) were developed. The test data sheet gathered data about the solution that subjects found by using the manual method. The questionnaire, which was filled out by subjects at the end of the test, contained questions that measured different aspects of user perception of usefulness and ease of use. Davis has developed and validated measurement constructs for perceived usefulness and perceived ease of use (Davis, 1989), and these constructs were validated later by other researchers (Adams et al., 1992). We adapted his questionnaire in 
our research, with some minor changes. The questionnaire contained ten questions where user perceptions were measured on a seven point Likert scale in which 1 means "strongly disagree", and 7 means "strongly agree".

\section{EXPERIMENTAL RESULTS}

A pilot test was conducted with seven subject to collect some initial data and to identify and correct potential problems in PASS, the test procedure and questionnaire, and to finalize the hypotheses before embarking on the full-scale test. The pilot test helped us to modify and improve the experimental design and interface as well as the hypotheses. A full-scale test was conducted with 26 third and fourth year Commerce undergraduate volunteers. The Acme and Merritt cases were randomly assigned to individual participating subjects; each case was assigned to 13 subjects. Subjects first solved the case that was assigned to them manually to find a portfolio, from the candidate projects, that maximized the net present value (NPV) of the portfolio while satisfying all of the existing constraints. Information that was required, such as project characteristics and existing constraints (for example, financial constraints, balancing criteria, and project interdependencies) was provided with the case. The results of the tests are described below.

\subsection{Data Consistency Test}

The reliability of responses to the questionnaire was evaluated with the Cronbach alpha test (Cronbach, 1951). Reliability assesses the internal consistency of the data; that is, how consistently individuals responded to questions. For perceived usefulness the Cronbach alpha was 0.67 , and for perceived ease of use it was 0.81 . A reliability score of 0.6 is usually considered acceptable (Nunnally, 1967). 


\subsection{Data Analysis}

The three hypotheses were examined, for small and larger problems respectively. In order to test each hypothesis, its sub-hypotheses were examined to see how well they supported the main hypothesis.

Hypothesis 1: The use of PASS improves the quality of project portfolio selection decisions.

Hypothesis 1 was analyzed using quantitative data collected during the test. Since a yes/no nominal scale was used for measurement, the Binomial test was used.

Test results for the small problem- Two subjects found infeasible solutions and only one subject found the optimal solution. Thus, in 12 of 13 cases PASS found a better portfolio than the manual method. Figure 2 shows the distribution of the feasible solutions found by subjects in comparison with the optimal solution. Five subjects found feasible solutions that were less than $1 \%$ below the optimal PASS solution. The test result for Hypothesis 1 for the small problem was highly significant $(\mathrm{p}=0.002)$. The null hypothesis was rejected and we can conclude that for the small problem "The use of PASS improves the quality of project portfolio selection decisions".

Test results for the larger problem- Three subjects found infeasible solutions and three subjects found the optimal solution. Thus, in 10 of 13 cases PASS found a better portfolio than the manual method. Figure 3 shows the distribution of the feasible solutions found by subjects in comparison with the optimal PASS solution. Six subjects found feasible solutions that were less than $1 \%$ below the optimal solution The Binomial test result for Hypothesis 1 for the small problem was significant $(\mathrm{p}=0.046)$. The null hypothesis was rejected and so we can conclude that for the larger problem "The use of PASS improves the quality of project portfolio selection decisions". 
Hypothesis 2- Users perceive PASS as a useful tool for project portfolio selection.

This hypothesis was examined by four sub-hypotheses using the answers to questions 1 to 4 , using the Median test.

Test results for the small problem- The statistical results for all of the first three sub-hypotheses were very significant $(\mathrm{p}=0.00)$. The null hypotheses for these questions were rejected. As a result, we can conclude that for the small problem "Users perceive PASS as a useful tool for project portfolio selection". This conclusion was also strongly supported by the result $(\mathrm{p}=0.00)$ for sub-hypothesis $\mathrm{H}_{2.4}$ that claims "Overall, PASS is a useful tool for project portfolio selection".

Test results for the larger problem- The statistical results for all of the first three sub-hypotheses were very significant $(\mathrm{p}=0.00)$. The null hypotheses for these questions were rejected. As a result, we can conclude that for the larger problem "Users perceive PASS as a useful tool for project portfolio selection". This conclusion is also strongly supported by the result $(\mathrm{p}=0.00)$ for sub-hypothesis $\mathrm{H}_{2.4}$ that claims "Overall, PASS is a useful tool for project portfolio selection".

Hypothesis 3- Users perceive PASS to be an easy to use tool.

This hypothesis was examined by six sub-hypotheses using the answers to questions 5 to 10 in the questionnaire, with the Median test.

Test results for the small problem- The statistical results for all of the first five sub-hypotheses were very significant $(\mathrm{p}=0.00)$. The null hypotheses for these questions were rejected. As a result, we can conclude that for the small problem "Users perceive PASS as an easy to use tool for project portfolio selection". This conclusion was also strongly supported by the result $\left(\mathrm{p}=0.00\right.$ ) for sub-hypothesis $\mathrm{H}_{3.6}$ that claims "Overall, PASS is easy to use". 
Test results for the larger problem- The statistical results for all of the first three sub-hypotheses were very significant $(\mathrm{p}=0.00)$. The null hypotheses for these questions were rejected. As a result, we can conclude that for the larger problem "Users perceive PASS as an easy to use tool for project portfolio selection". This conclusion was also strongly supported by the result $\left(\mathrm{p}=0.00\right.$ ) for sub-hypothesis $\mathrm{H}_{3.6}$ that claims "Overall, PASS is easy to use".

\section{Discussion}

In this paper, we proposed a framework for project portfolio selection. The proposed framework combines methods that are well grounded in theory with those that are easy to understand, and applies them in a logical manner. It also allows a choice of techniques by decision makers. Our approach is not intended to prescribe a certain portfolio, but rather to assist decision makers to find a satisfactory portfolio, which is as close to optimality as possible.

The implementation of the framework in our PASS decision support system gave an opportunity for a limited test of the on-line portion of the framework. Although the test results suggest that PASS is a useful tool, users will not adopt and use PASS unless they perceive it as a useful and easy to use tool. Our test results strongly supported the hypothesis that "users perceive PASS as a useful tool for project portfolio selection" in both the small and the larger problems. Moreover, the test results strongly supported the hypothesis that "Users perceive PASS as an easy to use tool" in both small and the larger problems. These two fundamental determinants of user acceptance show the high potential of using PASS in practical situations. Since solving problems without violating constraints would seem to be less difficult in smaller problems, we expected more subjects to find optimal or close to optimal solution in the small problem case. This did not happen, but to obtain an appropriate interpretation of these results would require 
additional experiments with a spectrum of problem sizes and constraint numbers and values. This was beyond the scope of our study.

Due to human limitations in handling larger and more sophisticated problems we expect even better support for this hypothesis in real world problems, since they are typically larger and more complex than the simplified example cases developed for this experiment. For example, since both of the cases that we developed for the test (Acme and Merritt) were intentionally simplified to prevent subject frustration at the outset, six subjects in each of the small and the larger problem cases were able to find a portfolio that was only $2 \%$ below the optimal solution. Although these results are acceptable in practical situations (considering that many of the model parameters, such as NPV, are calculated based on uncertain estimates), typical real world problems are not as small and simple as the cases developed for this test. As the number of projects or periods increases the solution space grows exponentially (addition of only one project or one time period doubles the solution space), and addition of real world constraints (such as having more than one limited resources, more than one project interdependency, and so on) makes real problems much more complex. As a result we do not expect as many people to find the optimal or close to optimal portfolios in a real environment as they did in this experiment with the simplified cases.

An additional effect in real world situation is the need to re-calculate solutions each time portfolio adjustments are made, so the impact of adjustments can be estimated. The same issue applies when decision makers want to perform sensitivity analysis to investigate the impact of changes in certain parameters (such as balancing criteria) on the solution and on the availability of resources. Clearly this would be impractical if manual calculations had to be re-done at each iteration, because of the long time delays involved. 
To examine the potential for applying the proposed framework and the PASS decision support system in practical situations we demonstrated PASS for two high-tech companies. These meetings were very useful and the participants were very supportive and enthusiastic about using the proposed framework and PASS. Officials in both firms raised major concerns and problems that they had with project portfolio selection. These are discussed briefly below, with proposed solutions arising from the use of our use of our framework and the PASS decision support system.

The department with whom we met in company A was an internal support organization which needed to select the best projects from among about 200 candidate projects. Because of the large number of projects, the pre-screening and screening stages in our framework would be useful in reducing the number of projects by eliminating from consideration any that clearly would not be appropriate to consider in the on-line stages. Some other problems in this organization, and how they could be resolved by using our framework and DSS included:

(i) There were candidate projects from more than one major category (e.g. customer requests, internal projects, etc.) with different objectives for each category. A solution would be to use overall importance weights derived for each category, and weights for attributes within each category. These could be derived off-line using an interactive procedure such as the Analytic Hierarchy Process (Saaty et al., 1980; Golden et al., 1989). These weights could then be used interactively to calculate the relative value of projects across all the categories, for input to the optimization stage of the on-line selection process.

(ii) The department had limited human expertise, with the added complication of interdependencies created by the fact that some of their workers had expertise in more than one area. These interactions can be resolved by including additional constraint equations in the 
optimization model. Suppose the company has three types of experts, each with different expertise: a) Expertise A: can only perform job 1, b) Expertise B: can only perform job 2, and c) Expertise C: can perform both jobs 1 and 2. Each of these types of expertise can be considered as a scarce resource and more constraints can be added to the model, to handle these resource interdependencies. For example, if the company has only 100 hours per month available from each type of the three expertises, the following sets of constraints would address this issue:

$\sum_{i=1}^{N} \sum_{j=1}^{k} R A(i, k+1-j)^{*} X_{i, j} \leq 200 \quad$ for $\mathrm{k}=1, \ldots \mathrm{T}$

$\sum_{i=1}^{N} \sum_{j=1}^{k} R B(i, k+1-j)^{*} X_{i, j} \leq 200 \quad$ for $\mathrm{k}=1, \ldots \mathrm{T}$

$\sum_{i=1 i=j=1}^{n} \sum^{k}\left(R A(i, k+1-j) * X_{i, j}+R B(i) * X_{i, k+1-j}\right) \leq 300 \quad$ for $\mathrm{k}=1, \ldots \mathrm{T}$

where $R A(i, k+1-j), R B(i, k+1-j)$ are respectively the amount of expertise $A$ and $B$, required by project $\mathrm{i}$ in period $\mathrm{k}, \mathrm{N}$ is the total number of projects being considered, and $\mathrm{T}$ is the last period in the planning horizon. $X_{i, j}$, the decision variable, is 1 if project $i$ is selected to start in period $j$ and is 0 otherwise.

Company B had two departments (new product research, and development), each with up to 12 projects underway at any time. A major concern was to achieve a balance among the projects included in each portfolio. Adding a constraint to the optimization model (similar to those which can be used to maintain portfolio balance in terms of risk and duration) would maintain the required balance between the portfolios. Obviously, this balance could be adjusted interactively by adding or deleting specific projects during the on-line adjustment stage. Other problems identified were: 
(i) An important requirement was to select previously specified mandatory projects and projects already started, and to ensure that ongoing projects "started" at time zero. This requires that ongoing projects be identified during data entry, and also displayed in a special manner by altering the interface iconic display. To ensure that ongoing projects start at time zero, the following constraint equations could be added to the optimization model.

$$
\sum_{j=1}^{T} X_{i 1}=1 \quad \text { for } \quad i \in S_{0} \text { where } S_{0} \text { is the set of ongoing projects }
$$

(ii) For certain special projects, the company needed to establish completion dates to meet delivery schedules. Adding the following constraint equations to the model would ensure that such projects, if selected, would be scheduled for completion before the due date. This was, of course, subject to the provision that it was feasible to do so within the time constraint.

$$
\sum_{j=1}^{L_{i}} j X_{i j}+D_{i} \leq L_{i}+1 \quad \text { for } i \in S_{f}
$$

where $S_{f}$ is the set of projects that should be finished before their delivery time $L_{i}$, and $D_{i}$ is the duration of project i.

These solutions can be implemented easily within the proposed framework and decision support system. This demonstrates the importance of the flexibility of the proposed framework in a real working environment, where there is no way to predict in advance all possible problems that may be faced. Additional research is needed to extend our work. For example, the proposed approach takes uncertainty and risk into consideration but it assumes that their parameters can be determined. However, risk estimation is a challenging task and more research is required to find suitable methods for evaluating project risks and their impact on portfolio selection. Depending on the type of application at hand and decision maker preferences about items to be balanced in the selected portfolio, different types of portfolio matrix displays can be provided. Research is 
required to find the most appropriate portfolio matrices to use_for information display in the adjustment stage of the proposed framework.

There are other important issues as well, such as representativeness of the displayed information, that should be taken into consideration. These may at times conflict with user friendliness of the system. For example, although the use of circles in displays to represent certain aspects of a project, such as its benefit, seems to be very suitable, some researchers contend that circles cause the decision makers to overvalue or undervalue the amounts that are represented (Cleveland and McGill, 1984). This issue should be considered in the portfolio selection environment. Finally, in most situations, a committee of decision makers makes portfolio selection decisions. Decision makers may often disagree in such situations and the DSS should provide support for reaching a consensus. This will also require adjusting the PASS concept to a group decision support system (GDSS) environment. 


\section{REFERENCES}

Adams, Dennis A., Nelson, R. Ryan, and Todd, Peter A., Perceived Usefulness, Ease of Use, and Usage of Information Technology: A Replication, MIS Quarterly, June 1992, 227-247.

Anderson, D.R., Sweeney, D.J. and Williams T.A., An Introduction to Management Science: Quantitative Approaches to Decision Making, West Publishing Co., NY, 1994.

Archer, N.P., Ghasemzadeh, F. (a), Portfolio selection techniques: A review and a suggested integrated approach, Innovation Research Center Working Paper 46, Hamilton. Ont.: School of Business, McMaster University, 1996.

Archer, N.P. and Ghasemzadeh, F. (b), An integrated framework for project portfolio selection. International Journal of Project Management, forthcoming.

Archer, N.P. and Ghasemzadeh, F. (c), A decision support system for project portfolio selection. International Journal of Technology Management, forthcoming.

Bard, J.F., Balachandra, R., and Kaufman, P.E., An interactive approach to R\&D project selection and termination, IEEE Transactions on Engineering Management, 1988, 35, 139-146.

Cleveland, S. W. and McGill, R., Graphical perception: theory, experimentation, and application to the development of graphical methods, Journal of American Statistical Association, 1984, 79.

Cooper, Robert G. Winning At New Products, Reading, MA: Addison-Wesley, 1993.

Cooper, R.G., Edgett, S.J. and Kleinschmidt, E.J., Portfolio management in new products: Lessons from the leaders-I, Research Technology Management, Sep.-Oct., 1997, 40(5), 16-28.

Cronbach, L.J., Coefficient alpha and the internal consistency of tests, Psychometrika, 1951, 16, 297-334.

Davis, Fred D., Perceived usefulness, perceived ease of use, and user acceptance of information technology, MIS Quarterly, September 1989, 319-340.

Davis, G.B. and Olson, M.H., Management Information Systems, New York, NY: McGraw-Hill, 1985.

Davis, F., Bagozzi, R., and Warshaw, P., User acceptance of computer technology: a comparison of two theoretical models, Management Science, 1989, 35(8), 982-1003.

De Maio, Adriano, Verganti, Roberto, \& Corso, Mariano, A multi-project management framework for new product development, European Journal of Operational Research, 1994, 78, 178-191. 
Dolk, Daniel R., \& Kottemann, Jeffrey E.. Model integration and a theory of models, Decision Support Systems, 1993, 9, 51-63.

Dos Santos, B.L., Selecting information system projects: problems, solutions and challenges, Proceedings of the Hawaii Conference on System Sciences, 1989, 1131-1140.

Dyer, J.S., Fishburn, P.C., Wallenius, J., and Zionts, S., Multiple criteria decision making, multi attribute utility theory: The next ten years, Management Science, 1992, 38(5), 645-654.

Evans, G.W., An overview of techniques for solving multi-objective mathematical programs, Management Science, 1984, 30(11),1268-1282.

Evans, G.W. and Fairbairn, R., Selection and scheduling of advanced missions for NASA using 0-1 integer linear programming, Journal of the Operational Research Society, 1989, 40(11),971981.

Geoffrion, A.M., An introduction to structured modeling, Management Science, 1987, 33(5), 547-588.

Ghasemzadeh, F., Archer, N.P., and Iyogun, P., A zero-one ILP model for project portfolio selection, Innovation Research Center Working Paper 59, Hamilton. Ont.: School of Business, McMaster University, 1996.

Golden, B.L., Wasil, E.A., and Levy, D.E., Applications of the analytic hierarchy process: A categorized, annotated bibliography. Published in The Analytic Hierarchy Process: Applications and Studies (Edited by Golden, B.L., Wasil, E.A., and Harker, P.T.), 1989, 37-58.

Hall, D.L. and Nauda, A., An interactive approach for selecting IR\&D projects, IEEE Transactions on Engineering Management, 1990, 37(2), 126-133.

Hess, S.W, Swinging on the branch of a tree: Project selection applications, Interfaces, 1993, 23(6), 5-12.

Jackson, B. Decision methods for selecting a portfolio of R\&D projects, Research Management, September-October 1983, 21-26.

Kira, D.S., Kusy, M.I, Murray, D.H., and Goranson B.J., A Specific Decision Support System (SDSS) to develop an optimal project portfolio mix under uncertainty, IEEE Transactions On Engineering Management, 1990, 37(3), 213-221.

Kottemann, Jeffrey E., \& Dolk, Daniel R., Model integration and modeling languages: A process perspective, Information Systems Research, 1992, 3(1), 1-16.

Liberatore, M.L. and Titus, G.J., The practice of management science in R\&D project selection, Management Science, 1983, 29, 962-974. 
Lucas, H.C., Computer Based Information Systems in Organizations, Science Research Associates, Chicago, II, 1973.

Martino J.P., Research and Development Project Selection, New York, NY: John Wiley \& Sons Inc., 1995.

Mathieu, R.G. and Gibson, J.E., A methodology for large scale R\&D planning based on cluster analysis, IEEE Transactions On Engineering Management, 1993, 30(3), 283-291.

Moore, G.C., and Benbasat, I., The development of an instrument to measure the perceived characteristics of adopting an information technology innovation, Information Systems Research, 1991, 2(3), 192-222.

Mukherjee, Kampan., Application of an interactive method for MOLIP in project selection decision: A case from Indian coal mining industry, International Journal of Production Economics, 1994, 36, 203-211.

Nunnally, J., Psychometric Theory, New York, McGraw-Hill, 1967.

Rasmussen, L.M., Zero-one programming with multiple criteria, European Journal of Operational Research, 1986, 26, 83-95.

Riggs, J. L., Brown, S.B., and Trueblood, R.P. Integration of technical, cost and schedule risks in project management, Computers and Operations Research., 1994, 21(5), 521-533.

Rousel, P.A., Saad, K.N., and Erickson, T.J. Third Generation R\&D, Cambridge, MA: Harvard Business School Press, 1991.

Saaty, Thomas L., Rogers, Paul C., \& Pell, Ricardo., Portfolio selection through hierarchies, The Journal of Portfolio Management, 1980, 6(3), 16-21.

Santhanam, R., Muralidhar, K., \& Schniederjans, M., A zero-one goal programming approach for information system project selection, OMEGA, 1989, 17(6), 583-593.

Schniederjans, M. and Santhanam, R., A multi-objective constrained resource information system project selection method, European Journal of Operational Research, 1993, 70, 244-253.

Turban, Efraim, Decision Support and Expert Systems (Fourth Edition), Englewood Cliffs, NJ: Prentice Hall, 1995. 
Project Analysis and Selection System [PASS]

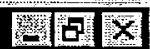

View Edt Gplions. Eint Help Exit

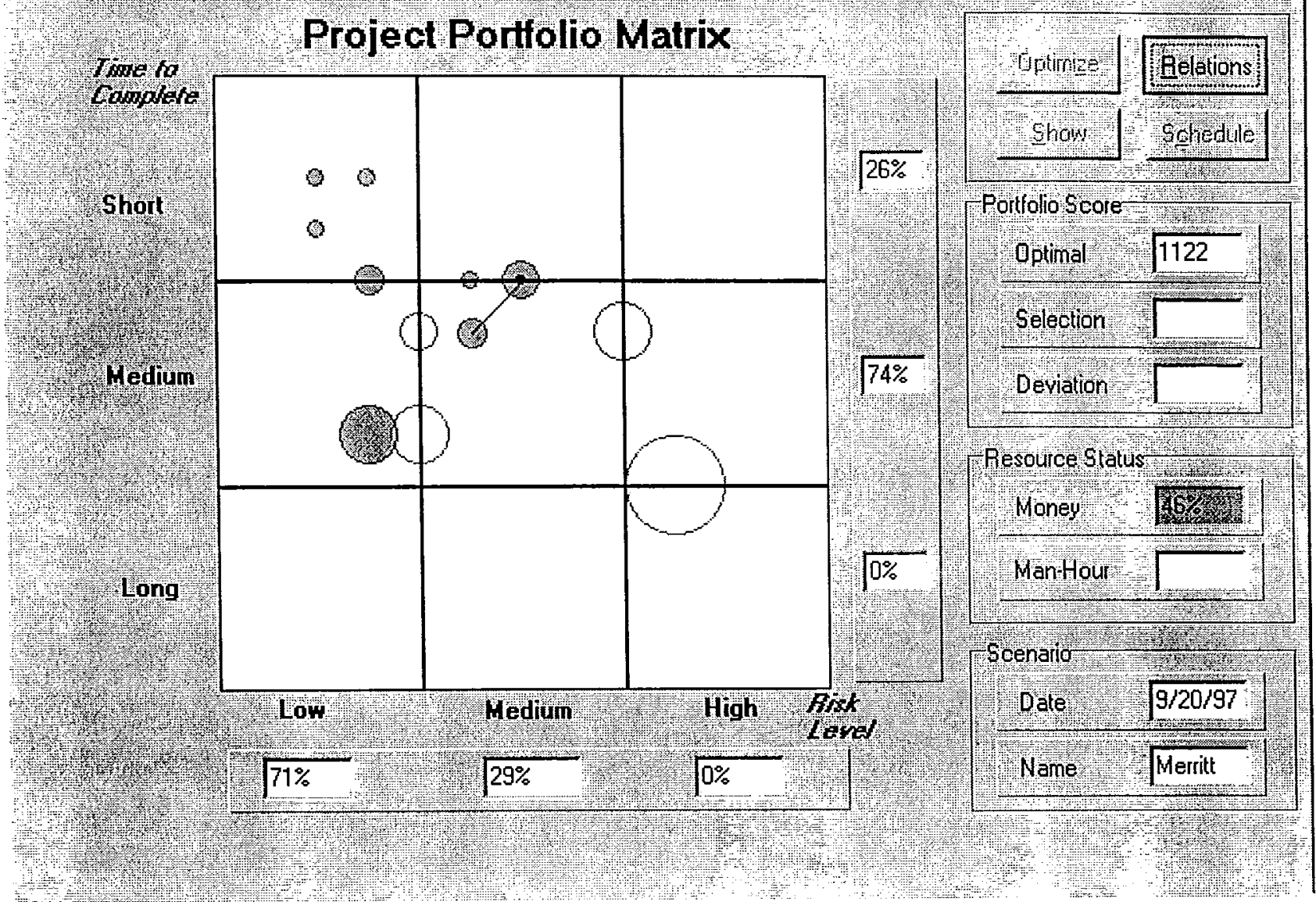

Figure 1 Project Portfolio Matrix 


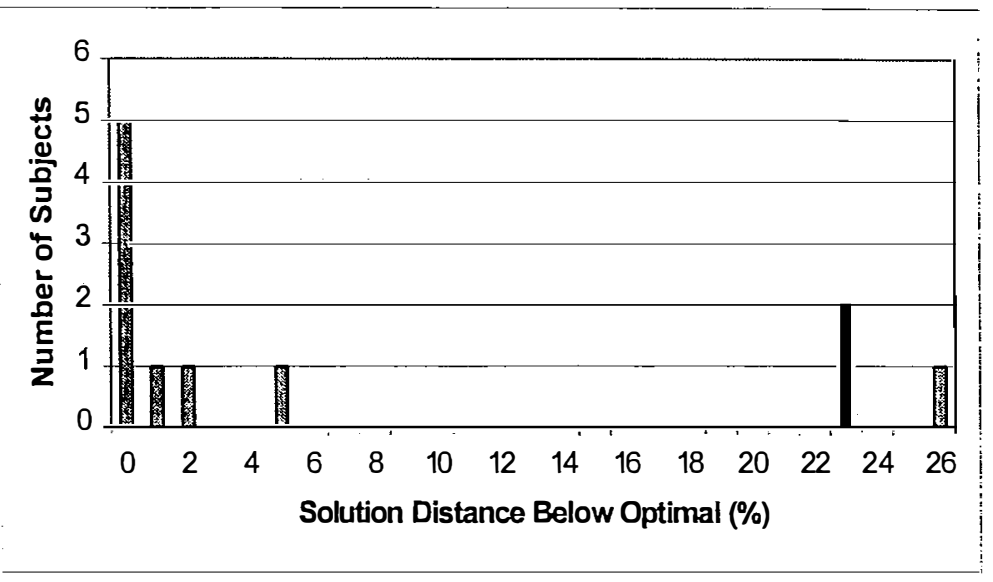

Figure 2 Histogram for the manual solutions found in the small problem

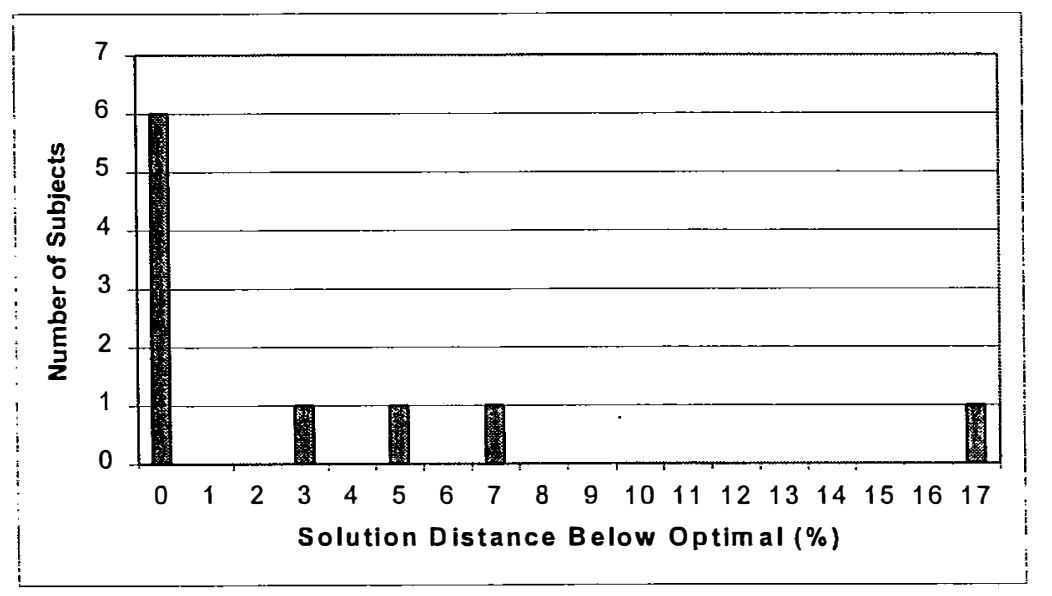

Figure 3 Histogram for the manual solutions found in the larger problem 


\section{APPENDIX}

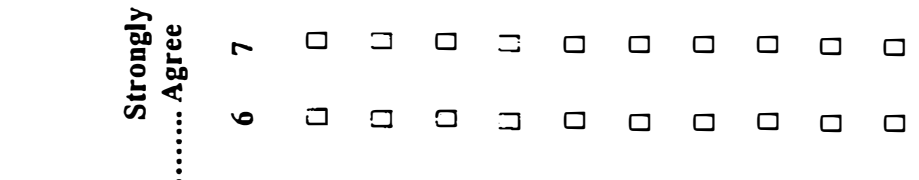

$\ddot{\ddot{g}}$

$\begin{array}{lllllllllll} & \square & \square & \square & \square & \square & \square & \square & \square & \square\end{array}$

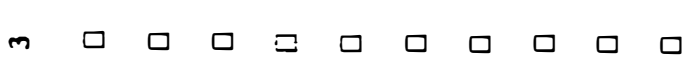

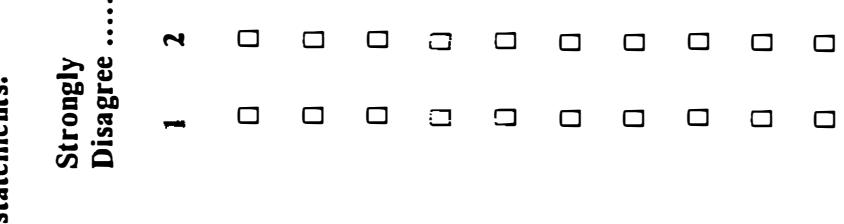

$\stackrel{\mathscr{E}}{ص}$

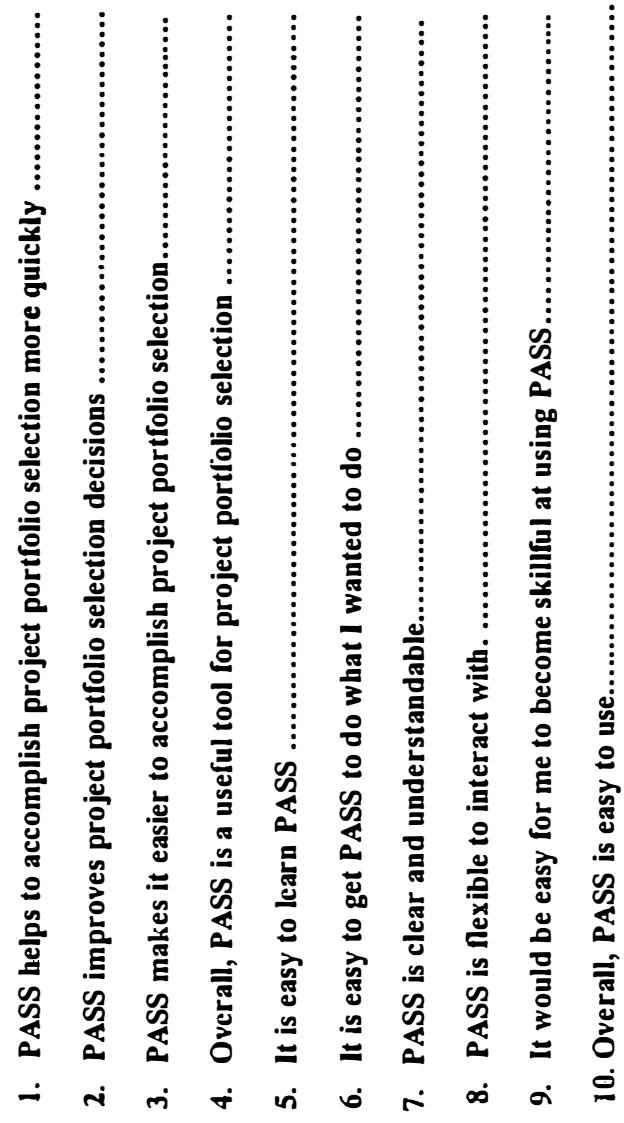




\section{MANAGEMENT OF INNOVATION AND NEW TECHNOLOGY WORKING PAPER SERIES}

1. R.G. Cooper and E.J. Kleinschmidt, "How the New Product Impacts on Success and Failure in the Chemical Industry", February, 1992.

2. R.G.Cooper and E.J. Kleinschmidt, "Major New Products: What Distinguishes the Winners in the Chemical Industry", February, 1992.

3. J. Miltenburg, "On the Equivalence of JT and MRP as Technologies for Reducing Wastes in Manufacturing, March, 1992.

4. J.B. Kim, I. Krinsky and J. Lee, "Valuation of Initial Public Offerings: Evidence from Korea", February, 1992.

5. M. Basadur and S. Robinson, "The New Creative Thinking Skills Needed for Total Quality Management to Become Fact, Not Just Philosophy", April, 1992.

6. S. Edgett and S. Parkinson, "The Development of New Services Distinguishing Between Success and Failure", April, 1992.

7. A.R. Montazemi and K.M. Gupta, "Planning and Development of Information Systems Towards Strategic Advantage of a Firm", April, 1992.

8. A.R. Montazemi, "Reducing the Complexity of MIS Innovation Through Hypermedia and Expert Systems", May, 1992.

9. M. Basadur and Bruce Paton, "Creativity Boosts Profits in Recessionary Times - Broadening the Playing Field", June, 1992.

10. Robert G. Cooper and Elko Kleinschmidt, "Stage-Gate Systems for Product Innovation: Rationale and Results", June, 1992.

11. S.A.W. Drew, "The Strategic Management of Innovation in the Financial Services Industry: An Empirical Study", July, 1992.

12. M. Shehata and M.E. Ibrahim, "The Impact of Tax Policies on Firms' R \& D Spending Behavior: The Case of R \& D Tax Credit", July, 1992. 
13. Willi H. Wiesner, "Development Interview Technology: Implications for Innovative Organizations", July, 1992.

14. Isik U. Zeytinoglu, "Technological Innovation and the Creation of a New Type of Employment: Telework", August, 1992.

15. John W. Medcof, "An Integrated Model for Teaching the Management of Innovation in the Introduction to Organizational Behaviour Course", October, 1992.

16. Min Basadur, "The Why-What's Stopping Analysis: A New Methodology for Formulating Ill-Structured Problems", October, 1992.

17. Stephen A.W. Drew, "Strategy, Innovation and Organizational Learning an Integrative Framework, Case Histories and Directions for Research", November, 1992.

18. Stephen A.W. Drew, "Innovation and Strategy in Financial Services", November, 1992.

19. Scott Edgett, "New Product Development Practices for Retail Financial Services", November, 1992.

20. Robert G. Cooper and Elko J. Kleinschmidt, "New Product Winners and Losers: The Relative Importance of Success Factors - Perception vs. Reality", November, 1992.

21. Robert G. Cooper and Elko J. Kleinschmidt, "A New Product Success Factors Model: An Empirical Validation", November, 1992.

22. Robert G. Cooper \& Elko J. Kleinschmidt, "Stage Gate Systems: A Game Plan for New Product Success", November, 1992.

23. Min Basadur, "Optimal Ideation-Evaluation Ratios", March, 1993.

24. Christopher K. Bart, "Gagging on Chaos", March, 1993.

25. Yufei Yuan, "The Role of Information Technology in Business Innovation", July, 1993.

26. Isik Urla Zeytinoglu, "Innovation in Employment: A Telework Experiment in Ontario", July, 1993.

27. John Miltenburg and David Sparling, "Managing and Reducing Total Cycle Time: Models and Analysis", August, 1993.

28. R.G. Cooper, C.J. Easingwood, S. Edgett, E.J. Kleinschmidt and C. Storey, "What Distinguishes the Top Performers in Financial Services", September, 1993.

29. B.E. Lynn, "Innovation and Accounting Research", September, 1993. 
30. Min Basadur and Peter Hausdorf, "Measuring Additional Divergent Thinking Attitudes Related to Creative Problem Solving and Innovation Management", November, 1993.

31. R.G. Cooper and E.J. Kleinschmidt, "Determinants of Time Efficiency in Product Development", December, 1993.

32. Christopher K. Bart, "Back to the Future: Timeless Lessons for Organizational Success", February, 1994.

33. Ken R. Deal and Scott J. Edgett, "Determining Success Criteria for New Financial Products; A Comparative Analysis of CART, Logit and Discriminant Analysis", February, 1995.

34. Christopher K. Bart and Mark C. Baetz, "Does Mission Matter?", February, 1995.

35. Christopher K. Bart, "Controlling New Products: A Contingency Approach", February, 1995.

36. Christopher K. Bart, "Is Fortune Magazine Right? An Investigation into the Application of Deutschman's 16 High-Tech Management Practices", February, 1995.

37. Christopher K. Bart, "The Impact of Mission on Firm Innovativeness", February, 1995.

38. John W. Medcof, "Transnational Technology Networks", April, 1995.

39. R.G. Cooper and E.J. Kleinschmidt, "Benchmarking the Critical Success Factors of Firms' New Product Development Programs", April, 1995.

40. John W. Medcof, "Trends in Selected High Technology Industries", July, 1995.

41. Robert C. Cooper \& E.J. Kleinschmidt, "Benchmarking Firms' New Product Performance \& Practices", September, 1995.

42. Min Basadur and Darryl Kirkland, "Training Effects on the Divergent Thinking Attitudes of South American Managers", November, 1995.

43. Min Basadur, "Organizational Development Interventions for Enhancing Creativity in the Workplace", November, 1995.

44. Min Basadur, "Training Managerial Evaluative and Ideational Skills in Creative Problem Solving: A Causal Model", December, 1995. 
45. Min Basadur, Pam Pringle and Simon Taggar, "Improving the Reliability of Three New Scales Which Measure Three New Divergent Thinking Attitudes Related to Organizational Creativity", December, 1995.

46. N. P. Archer and F. Ghasemzadeh, "Project Portfolio Selection Techniques: A Review and a Suggested Integrated Approach", February, 1996.

47. Elko J. Kleinschmidt, "Successful new product development in Australia: An empirical analysis", February, 1996.

48. Christopher K. Bart, "Industrial Firms \& the Power of Mission," April, 1996.

49. N. P. Archer and F. Ghasemzadeh, "Project Portfolio Selection Management through Decision Support: A System Prototype," April, 1996.

50. John W. Medcof, "Challenges in Collaboration Management in Overseas Technology Units," April, 1996.

51. Susan L. Kichuk and Willi H. Wiesner, "Personality and Team Performance: Implications for Selecting Successful Product Design Teams," May, 1996.

52. Susan L. Kichuk and Willi H. Wiesner, "Selection Measures for a Team Environment: The Relationships among the Wonderlic Personnel Test, The Neo-FFI, and the Teamwork KSA Test, "May, 1996.

53. Susan L. Kichuk and Willi H. Wiesner, "Personality, Performance, Satisfaction, and Potential Longevity in Product Design Teams," June, 1996.

54. John W. Medcof, "Learning, Positioning and Alliance Partner Selection," June, 1996.

55. Scott J. Edgett, "The New Product Development Process for Commercial Financial Services," July, 1996.

56. Christopher K. Bart, "Sex, Lies \& Mission Statements," September, 1996.

57. Stuart Mestelman and Mohamed Shehata, "The Impact of Research and Development Subsidies on the Employment of Research and Development Inputs," November, 1996.

58. Mark C. Baetz and Christopher K. Bart, "Developing Mission Statements Which Work," November, 1996.

59. Fereidoun Ghasemzadeh, Norm Archer and Paul Iyogun, "A Zero-One Model for Project Portfolio Selection and Scheduling," December, 1996. 
60. R. G. Cooper, S. J. Edgett, E. J. Kleinschmidt, "Portfolio Management in New Product Development: Lessons from Leading Firms," February 1997.

61. R. G. Cooper, S. J. Edgett, E. J. Kleinschmidt, "Portfolio Management in New Product Development: Lessons from Leading Firms -- Part II," February 1997.

62. C. K. Bart, "A Comparison of Mission Statements \& Their Rationales in Innovative and Non-Innovative Firms," February 1997.

63. R. Bassett, N. P. Archer and W. G. Truscott, "Data Webs: An Evaluation of an Innovative Information Management Tool that Integrates Databases with the World Wide Web," April 1997.

64. S. Taggar, "Intelligence, Personality, Creativity and Behaviour: The Antecedents of Superior Team Performance," April 1997.

65. R. Deaves and I. Krinsky, "New Tools for Investment Decision-Making: Real Options Analysis," May 1997.

66. J. W. Medcof (ed.), "Trends and Events in Selected High Technology Industries," May, 1997. (On the WEB only)

67. C. K. Bart, "Product Innovation Charters: A State-of-the-Art Review," May, 1997.

68. John W. Medcof, "Strategic Contingencies and Power in Networks of Internationally Dispersed R\&D Facilities", August, 1997.

69. John W. Medcof, "Research Intensity and the Identification of High Technology Industries," September, 1997.

70. Christopher K. Bart and John C. Tabone, "Mission Statements in the Not-for-profit Health Care Sector: A State of the Art Review," September, 1997.

71. Elko J. Kleinschmidt, "In-house and Partnership New Product Development in Austria: An Empirical Analysis on Outcome and Explanatory Factors," October, 1997.

72. Robert G. Cooper, Scott J. Edgett and Elko J. Kleinschmidt, "R\&D Portfolio Management Best Practices: Methods Used \& Performance Results Achieved," January, 1998.

73. Christopher K. Bart and Simon Taggar, "A Model of the Impact of Mission Rationale, Content, Process and Alignment on Firm Performance," March, 1998.

74. Christopher K. Bart, John Parkinson and Simon Taggar, "The Implementation of Strategy: Behavioural vs Budgetary Approaches and the Effect of Participation," March, 1998. 
75. John W. Medcof, "The Resource Based View and the New Competitive Landscape: Characterizing Positions of Dynamic Capability," May, 1998.

innova/papers.irc 